\title{
The magnetic properties of Serbian loess and its environmental significance
}

\author{
LIU XiuMing ${ }^{1,2,3^{*}}$, LIU Zhi ${ }^{1}$, LÜ Bin ${ }^{1}$, MARKOVIĆ S B ${ }^{4}$, CHEN JiaSheng ${ }^{1}$, GUO Hui ${ }^{1}$, \\ MA MingMing ${ }^{1}$, ZHAO GuoYong ${ }^{1} \&$ FENG Hua ${ }^{1}$ \\ ${ }^{1}$ Research School of Arid Environment \& Climate Change, Lanzhou University, Lanzhou 730000, China; \\ ${ }^{2}$ School of Geographical Sciences, Fujian Normal University, Fuzhou 350007, China; \\ ${ }^{3}$ Department of Environment and Geography, Macquarie University, Sydney NSW 2109, Australia; \\ ${ }^{4}$ Chair of Physical Geography, Faculty of Sciences, University of Novi Sad, Trg Dositeja Obradovića 3, 21000 Novi Sad, Serbia
}

Received March 17, 2012; accepted July 3, 2012; published online August 27, 2012

This paper reports a loess-paleosol sequence located in the Danube River basin, Serbia, which formed at least since the latest part of the early Pleistocene, and before the paleomagnetic B/M boundary. Various magnetic parameters of the Serbian V- $\mathrm{L}_{1}-\mathrm{V}-\mathrm{S}_{4}$ loess-paleosol sequence have been measured and analyzed in the Titel Loess Plateau. These parameters show a very similar magnetic behavior compared with that of the Chinese loess. There is a general positive relationship between magnetic susceptibility $(\chi)$ and pedogenesis. The main contributors to $\chi$ are the magnetic grains of SP (superparamagnetic) and SD (single domain) magnetic domains, while MD (multi domain) contributes only a small percentage. The difference in $\chi$ between loess and paleosol mainly is caused by pedogenesis. The very fine magnetic minerals increase gradually with increasing soil development (from loess to soil), and they lead to higher $\chi$. The thermomagnetic curves show thatmagnetic minerals in the loess layers are magnetite and maghemite, both providing a major contribution to $\chi$. In contrast the paleosol layers mainly are composed of magnetite, with almost no or a very small amount of maghemite, as implied by a reversible thermomagnetic behavior. This indicates that pedogenic conditions during $\mathrm{V}-\mathrm{S}_{3}$ and $\mathrm{V}-\mathrm{S}_{4}$ strong soil development have resulted in maghemite that is no longer stable, and has been resolved or converted to other stable phase minerals. This likely indicates that soil moisture during V-S $\mathrm{S}_{3}$ and $\mathrm{V}-\mathrm{S}_{4}$ development exceeded a critical condition of maghemite stability.

Serbian loess, magnetic properties, pedogenesis, paleoenvironment

Citation: Liu X M, Liu Z, Lü B, et al. The magnetic properties of Serbian loess and its environmental significance. Chin Sci Bull, 2013, 58: 353-363, doi: $10.1007 / \mathrm{s} 11434-012-5383-9$

Over the past 30 years, studies on Chinese loess and paleoclimate have obtained remarkable achievements. Currently, Chinese loess is thought to be one of the three most important types of paleoenvironmental records including deepsea deposits, and Antarctic and Greenland ice core $[1,2]$. Magnetic susceptibility $(\chi)$ and grain size are two of the most useful proxies reflecting paleoclimate change. The $\chi$, as a summer monsoon proxy, has a positive correlation with intensity of pedogenesis: $\chi$ is relatively low in loess layers, but high in paleosols. This phenomenon is explained by the

*Corresponding author (email: xliu@ fjnu.edu.cn) fact that there are more fine-grained maghemite/magnetite grains formed in the process of pedogenesis [3,4]. However, as study areas expand in China and overseas [5-11], different modes in relation to Chinese Loess Plateau have been been reported on, such as in Alaska [5,9,11] and Siberia $[6,10]$. In these deposits, the magnetic behaviors show another extreme case: $\chi$ in loess layers is relatively high, but low in paleosols. Furthermore, the loess in New Zealand and Argentina [12] show no clear relationship between $\chi$ and pedogenesis. The loess in Ili of Xinjiang, which has two closely assocated loess sections, yields a positive correlation in one and a negative correlation in the other [13]. With 
respect to the negative correlation in Alaskan loess, some researchers have proposed the "wind velocity" hypothesis as an explanation in which the inverse relationship is reflected in the magnitude of an aeolian ferromagnetic component of consistent mineralogy, the grain size of which is related to the average wind velocity [5]. Subsequently, the researchers have also conducted wind tunnel experiments with artificial magnetite to test and validate this hypothesis [14]. However, if there was too much moisture for pedogenesis, some maghemite/magnetite would become unstable and would be transformed into goethite/limonite. This process also may cause the negative correlation between $\chi$ and pedogenesis [9-11]. Therefore, a better understanding of the relation between $\chi$ and paleoclimate may be achieved by understanding the prerequisite condition for paleoclimatic reconstruction. Clearly, in different climatic conditions, the relationship may be different. The Chinese Loess Plateau model may be just one of the various scenarios. Whether there are more styles will need to be determined through analysis of more loess sections in different areas with various environmental conditions.

Located southeastern Europe, Serbia is an inland country of the central Balkans. With an area of $88000 \mathrm{~km}^{2}$ it was formerly part of Yugoslavia. The climatic conditions are those of a temperate continental climate. The Serbian loesspaleosol sequences are some of the oldest and most complete eolian sediments in Europe. A recent paleomagnetic study reported the $\mathrm{B} / \mathrm{M}$ boundary in the lower part of the Stari Slankamen section [15]. Over the past several years, researchers have conducted much work in this area, including detailed descriptions of the sedimentary sections [16-18] using grain size $[19,20]$ and carbonate [21] analyses, and magnetic susceptibility $[17,18,21]$ to reconstruct paleoclimatic information. Other studies have used paleomagnetism [15], amino acid racemization [19] and OSL [22,23] to build a geochronology. However, few studies have been conducted on rock magnetism and $\chi$ mechanisms. The purpose of this study is to understand the basic magnetic characteristics in Serbian loess. By systemic measurement and analysis of Serbian $\mathrm{V}-\mathrm{L}_{1}-\mathrm{V}-\mathrm{S}_{4}$ loess-paleosol samples the aim is to better understand the increasing $\chi$ mechanism with respect to paleoenvironmental evolution.

\section{Sampling and methods}

The Danube Plain is northern Serbia. The area contains widely distributed Quaternary eolian loess (Figure 1). Study samples were collected from the Titel Loess Plateau (Figure 1), which is located $5 \mathrm{~km}$ north of the Danube River. The eastern edge of the area is adjacent to the Tisa River (Figure 1). The present-day annual average temperature of the region is $10.9^{\circ} \mathrm{C}$, and annual average rainfall is $574 \mathrm{~mm}$, while evaporation is $778 \mathrm{~mm}$. The Titel Loess Plateau is interpreted as a "loess island" [20], with a maximum extension of about $16 \mathrm{~km}$ and maximum width of about $7.2 \mathrm{~km}$. The thickness of loess deposits ranges from 35 to $55 \mathrm{~m}[24,25]$. Around the plateau, there are four good loess sections exposed (Figure 1). The study samples were taken at 4 $\left(45^{\circ} 17.768^{\prime} \mathrm{N}, 20^{\circ} 11.319^{\prime} \mathrm{E}, H=119+5 \mathrm{~m}\right)$ from the top to V-S. Marković et al. [17] designated the loess-palaeosol unit names in North Serbia following the Chinese loess stratigraphic system, but inserting the prefix "V" used to refer to the standard Pleistocene loess-palaeosol stratigraphy

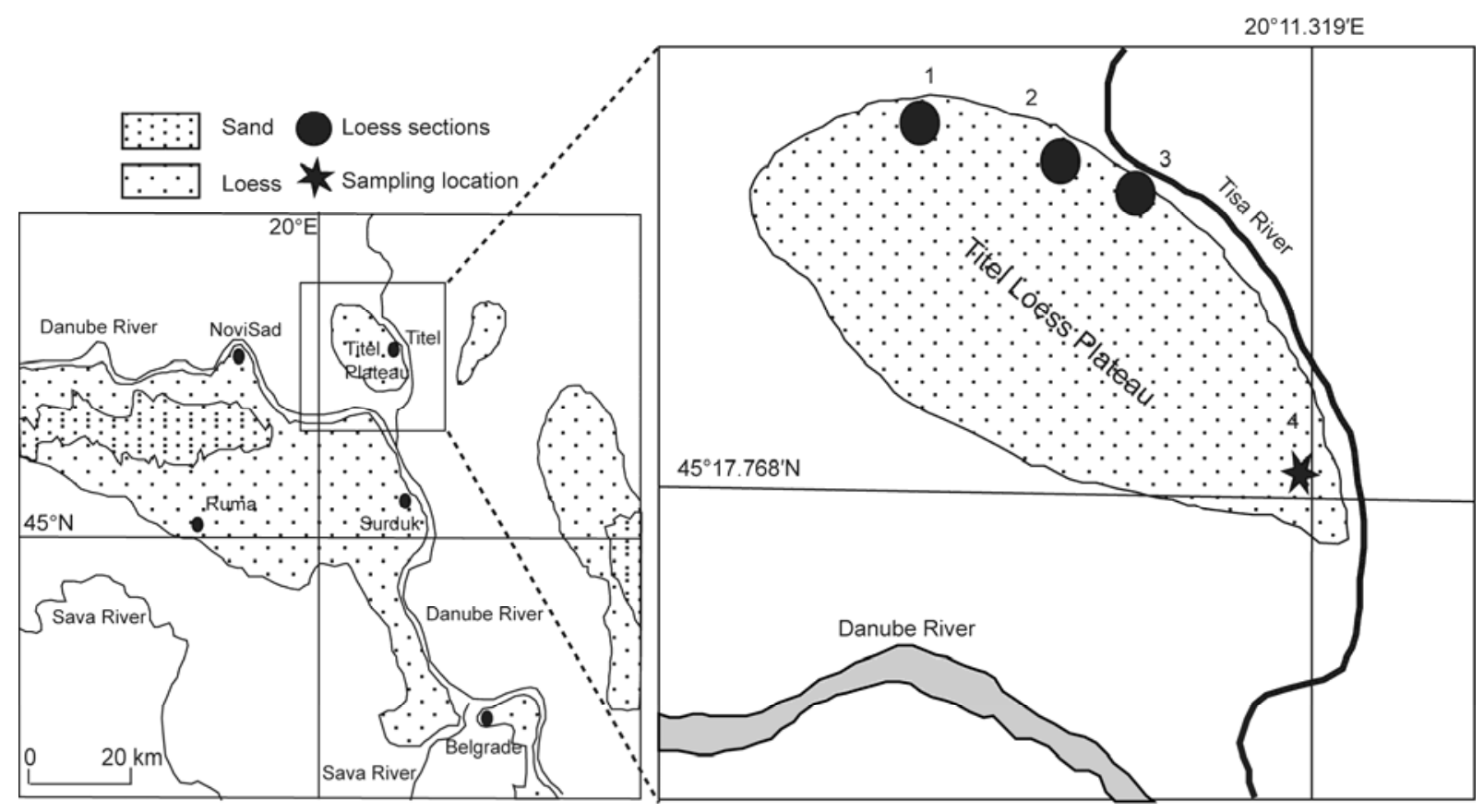

Figure 1 Study area and sampling locations (modified from [21]). 
in the Vojvodina region. The lower part of the synthetic loess profile of the Titel loess plateau is highly affected by hydromorphic features. In total, 70 loess samples were collected.

The samples were air-dried and grinded indoors, then they were weighed and packed in non-magnetic plastic boxes. The magnetic parameters were measured, including low-frequency magnetic susceptibility $\left(\chi_{\mathrm{lf}}\right)$, high-frequency magnetic susceptibility $\left(\chi_{\mathrm{hf}}\right)$, anhysteretic remanent magnetization (ARM), isothermal remanent magnetization (IRM), and saturation isothermal remanent magnetization (SIRM). Several representative samples were selected to measure low-temperature magnetic susceptibility, magnetic hysteresis loops and thermomagnetic curves $(J-T)$. The representative samples were chosen according to their characteristics of magnetic susceptibility. Magnetic susceptibility was measured at low frequency $\left(0.47 \mathrm{kHz}, \chi_{\mathrm{lf}}\right)$ and high frequency $\left(4.7 \mathrm{kHz}, \chi_{\mathrm{hf}}\right)$, using a Bartington MS2 meter. Percentage frequency-dependent magnetic susceptibility $\left(\chi_{\mathrm{fd}} \%\right)$ was calculated with: $\chi_{\mathrm{fd}}(\%)=\left(\left(\chi_{\mathrm{lf}}-\chi_{\mathrm{hf}}\right) / \chi_{\mathrm{lf}}\right) \times 100$. ARM was measured in a Minispin magnetometer after magnetization with an AF demagnetizer. The peak AF field was 100 $\mathrm{mT}$ and the DC field was $50 \mu \mathrm{T}$. IRM was acquired in progressively increasing magnetic fields with a pulse magnetizer and, measured in a Minispin Magnetometer after each magnetization. The IRM acquired in the $1 \mathrm{~T}$ field was defined as SIRM. Remanent coercivity $\left(H_{\mathrm{cr}}\right)$ is the required magnetic field that makes SIRM reach zero with reverse magnetic field. Low-temperature susceptibility was measured with a Kappabridge (KLY-3S, liquid Nitrogen cooled to $\left.-195^{\circ} \mathrm{C}\right)$. Magnetic hysteresis loops and thermomagnetic curves $(J-T)$ were measured with a variable field translation balance (VFTB). All the experiments were carried out at the Key Laboratory of Western Environmental Systems (Ministry of Education), Lanzhou University.

\section{Results}

\subsection{Room-temperature properties}

$\chi$ depends on the complexity of magnetization of the study materials [26], which is associated with the types, magnetic domains and contents contained in the samples. In addition, this is a parameter of the samples' overall magnetic strength. In Serbian loess, $\chi$ in the loess layers becomes lower, and in the paleosol the layers become higher. The four distinct peaks correspond to the paleosol layers $\left(\mathrm{V}-\mathrm{S}_{1}, \mathrm{~V}-\mathrm{S}_{2}, \mathrm{~V}-\mathrm{S}_{3}\right.$, $\left.\mathrm{V}-\mathrm{S}_{4}\right)$ and the four troughs are named after the loess layers $\left(\mathrm{V}-\mathrm{L}_{1}, \mathrm{~V}-\mathrm{L}_{2}, \mathrm{~V}-\mathrm{L}_{3}, \mathrm{~V}-\mathrm{L}_{4}\right)$. In this profile, the relationship between $\chi$ and pedogenesis is similar to that of the Chinese Loess Plateau [27]. They all show a positive correlation of $\chi$ with pedogenic development. The $\chi$ values range from $(1.44-11.14) \times 10^{-7} \mathrm{~m}^{3} / \mathrm{kg}$. The highest value appeared in $\mathrm{V}-\mathrm{S}_{3}$, and the lowest value in $\mathrm{V}-\mathrm{L}_{4}$. The average of all samples is $5.19 \times 10^{-7} \mathrm{~m}^{3} / \mathrm{kg}$. The percentage frequency-dependent susceptibility $\left(\chi_{\mathrm{fd}} \%\right)$ reflects the fine-grained signals near the boundary $(0.03 \mu \mathrm{m})$ of superparamagnetic (SP) and single domain (SD) particles [28]. These fine-grained maghemite/magnetite particles, which increased in abundance with pedogenesis, often are interpreted important to the analysis of paleoenvironmental change [4]. The $\chi_{\mathrm{fd}} \%$ of Serbian loess is distributed from $1.38 \%$ to $10.68 \%$, and the average is $6.63 \%$. Paleosol layers show higher values, while loess layers yielded lower values of $\chi_{\mathrm{fd}} \%$, and $\chi$ values have a good corresponding relationship (Figure 2). The fitting in Figure 3(a) shows that, as $\chi$ increases, the $\chi_{\mathrm{fd}} \%$ first increase rapidly, but it becomes saturated gradually when it reaches the strong pedogenic phase. This indicates that $\chi$ is closely related to the SP maghemite/magnetite particles formed in the process of pedogenesis. As SD particles have a relatively stronger ability to carry remanence than SP and MD particles, ARM often is used to identify the content of SD particles in the samples. The ARM results of Serbian loess show that the variation trend of the ARM curve is extremely consistent with $\chi$ (Figure 2), and both have a good linear correlation. This correlation coefficient reaches 0.962 (Figure 3(b)), implying that the ferrimagnetic SD particles play an important role in the $\chi$. The morphology of the $\chi_{\mathrm{ARM}} / \chi$ curve also is close to $\chi$. The ratio value always is higher in the paleosol layers than loess layers (Figure 2), indicating that the magnetic particles in paleosol layers are finer than loess layers. Considering paleosol layers alone, the $\chi_{\text {ARM }} / \chi$ ratio from $\mathrm{V}-\mathrm{S}_{4}$ to $\mathrm{V}-\mathrm{S}_{1}$ has a gradual decreasing trend. IRM is the remanence magnetization after imposing different magnetic fields on the V-Samples at the same temperature (room temperature). SIRM refers to the IRM acquired in the highest magnetic field. The SIRM of this profile shows an excellent correlation with $\chi$ (Figures 2 and $3(c))$. This may imply that the kinds and size-distribution of magnetic minerals in the samples are consistent. In the study of rock magnetism, magnetic minerals are usually divided into soft and hard magnetism. The magnetic minerals which easily are saturated under low field ( $0.3 \mathrm{~T}$ or less) are called soft magnetic components, such as magnetite and maghemite. The minerals that do not easily become saturated or require a higher magnetic field $(>0.3 \mathrm{~T})$ are called hard components, such as hematite and goethite. Therefore, the ratio of $\mathrm{IRM}_{300 \mathrm{mT}} / \mathrm{SIRM}$ can roughly indicate the percentage of soft magnetic component in the samples. The $\mathrm{IRM}_{300 \mathrm{mT}} / \mathrm{SIRM}$ curve in Figure 2 shows that most of the ratio values have already exceeded $95 \%$ in this profile, indicating either loess or paleosol, and that the magnetic minerals in samples mainly are soft magnetite and/or maghemite (refer to below thermomagnetic analysis). Similar to the $\chi$ curve, the ratio of $\mathrm{IRM}_{300 \mathrm{mT}} / \mathrm{SIRM}$ is reduced in the loess layers (although the values are still high) and raised in the paleosol layers. This indicates that soil samples contain more soft magnetic minerals, which also is a factor that causes the $\chi$ enhancement. The ratio of SIRM/ $\chi$ also can be 


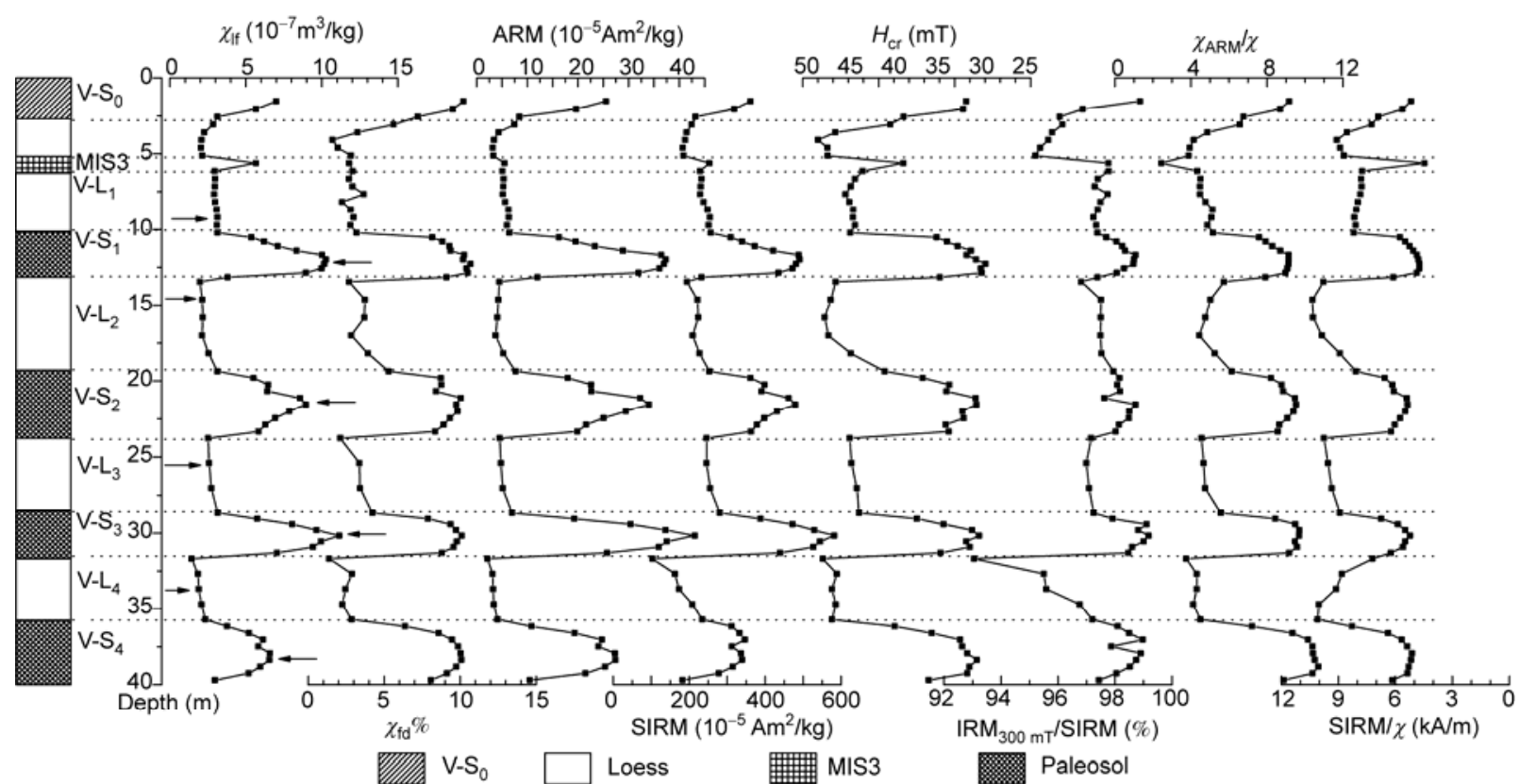

Figure 2 Variation curves of magnetic parameters from Serbian loess. Arrows show positions where samples were analyzed in detail, and the sampling depth [29].
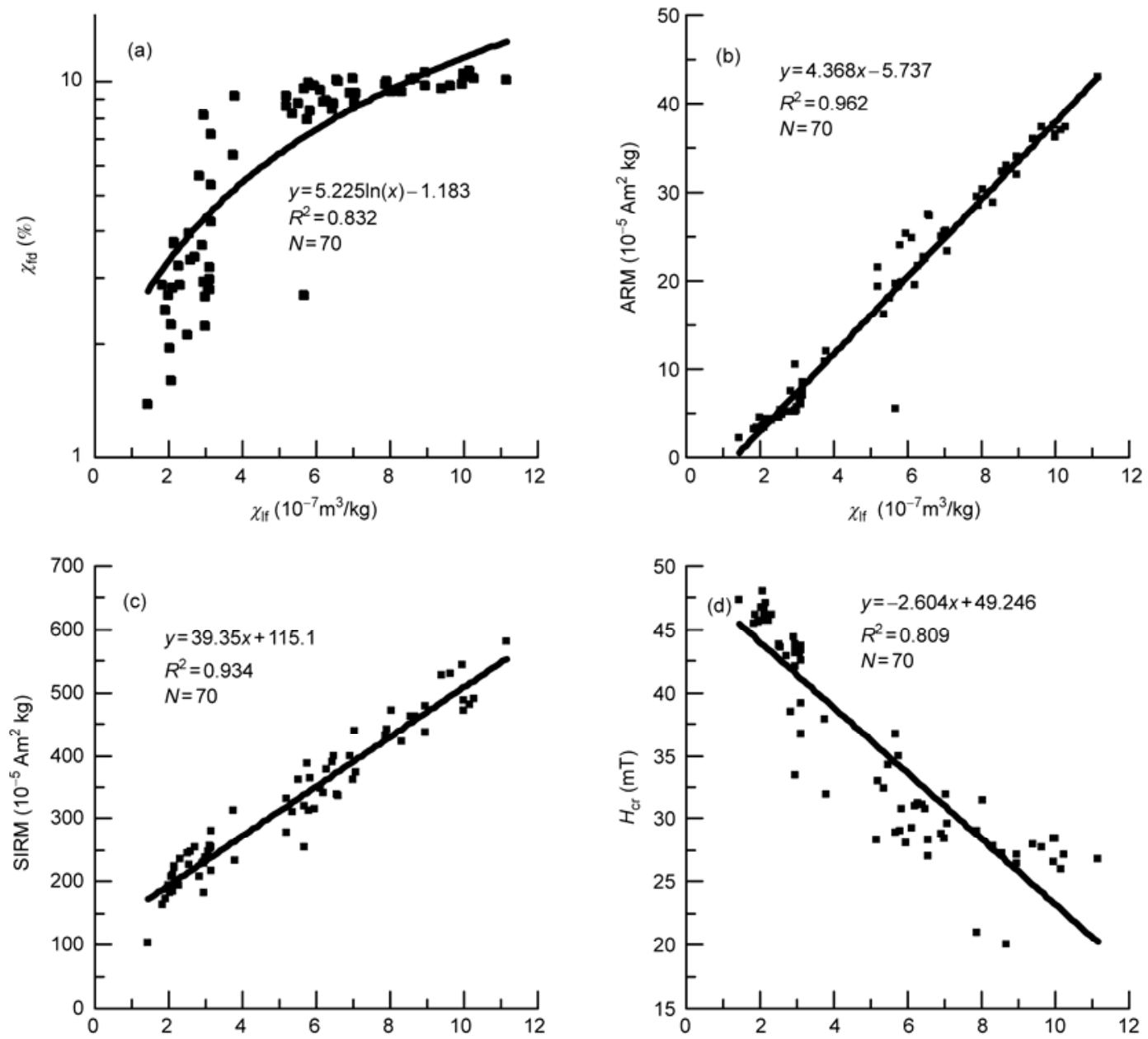

Figure 3 Correlation analysis between $\chi$ and $\chi_{\mathrm{fd}} \%$, ARM, SIRM, $H_{\mathrm{cr}}$. 
used to estimate the relative particles of magnetic minerals. This value will increase as the particles become finer, as indicated in the SIRM $/ \chi$ curve of the profile shown in Figure 2. This curve shape is similar to the curves of $\chi$ and $\chi_{\mathrm{ARM}} / \chi$, both increasing in the soil layers and decreasing in the loess layers. This also indicates that the magnetic particles in soil layers are finer than in the loess layers. The $H_{\mathrm{cr}}$ of the samples were lower than $50 \mathrm{mT}$, and the average was $35.72 \mathrm{mT}$. This further indicates that low coercivity ferrimagnetic minerals (magnetite and/or maghemite) are the main magnetic minerals in the samples. Overall, $H_{\mathrm{cr}}$ and $\chi$ have a good negative correlation (Figure 2), whereby as the $\chi$ values increase, $H_{\text {cr }}$ decreases linearly (Figure $3(\mathrm{~d})$ ). This trend suggests that during pedogenic development, there is a production of many extra fine-grained magnetic minerals with higher $\chi$ but lower $H_{\mathrm{cr}}$.

Based on the $\chi$ values, we selected 43 samples from different depths to measure the hysteresis loops and thermomagnetic curves. The magnetic field of hysteresis loop measurements are from -1 to $1 \mathrm{~T}$. In order to illustrate the low-field characteristics clearly, Figure 4 shows data from -0.5 to $0.5 \mathrm{~T}$ only. The hysteresis loops and hysteresis parameters shown in Figure 4 are for typical samples (Figure 2, arrows) selected from $\mathrm{V}-\mathrm{L}_{1}$ to $\mathrm{V}-\mathrm{S}_{4}$. The $M_{\mathrm{s}}$ values in loess layers are lower than in the paleosol layers. $M_{\mathrm{s}}$ is not usually considered to be affected by magnetic particles, and mainly reflects the total content of magnetic minerals in the samples. Thus, the $M_{\mathrm{s}}$ values of these samples indicate that the total content of magnetic minerals in paleosol layers is higher than in loess layers. $M_{\mathrm{rs}} / M_{\mathrm{s}}$ and $H_{\mathrm{cr}} / H_{\mathrm{c}}$ in the loess and paleosol layers have no distinct change, and if these data were drawn on a Day plot, most points would be concentrated in the PSD area. The $H_{\mathrm{c}}$ values are similar to the $H_{\mathrm{cr}}$, which reflects the hardness of the magnetic minerals. The results are high in the loess layers and low in the paleosol layers.

\subsection{Low-temperature susceptibility}

Low-temperature susceptibility curves can effectively reflect the magnetic domain information of magnetite in samples [30]. This helps us analyze whether the SP, SD or MD magnetites are the major characteristics $[26,31]$. We measured low-temperature susceptibility within the same samples used to construct the hysteresis loop in Figure 4. These results are shown in Figure 5. All loess and paleosol samples display the Verwey transition near $-150^{\circ} \mathrm{C}$, but not very clearly (Figure 5), indicating that a certain amount of coarse MD magnetites were present. In addition, with the increase in temperature, the values of low-temperature susceptibility change slightly, and they approximate the horizontal scale. This trend likely indicates that the SD magnetite is an important component in the samples. The main difference between loess and paleosol is the slope coefficient: the loess samples show a slight decrease with increasing temperature. This demonstrates that the major magnetic minerals in these samples obey Curie's law (magnetic susceptibility of paramagnetism is inversely proportional to temperature). This property indicates that the loess samples contain a relatively large proportion of paramagnetic minerals. Conversely, the paleosol samples increase the $\chi$ with increasing temperature $\left(\mathrm{V}-\mathrm{S}_{3}\right.$ and $\left.\mathrm{V}-\mathrm{S}_{1}\right)$ or
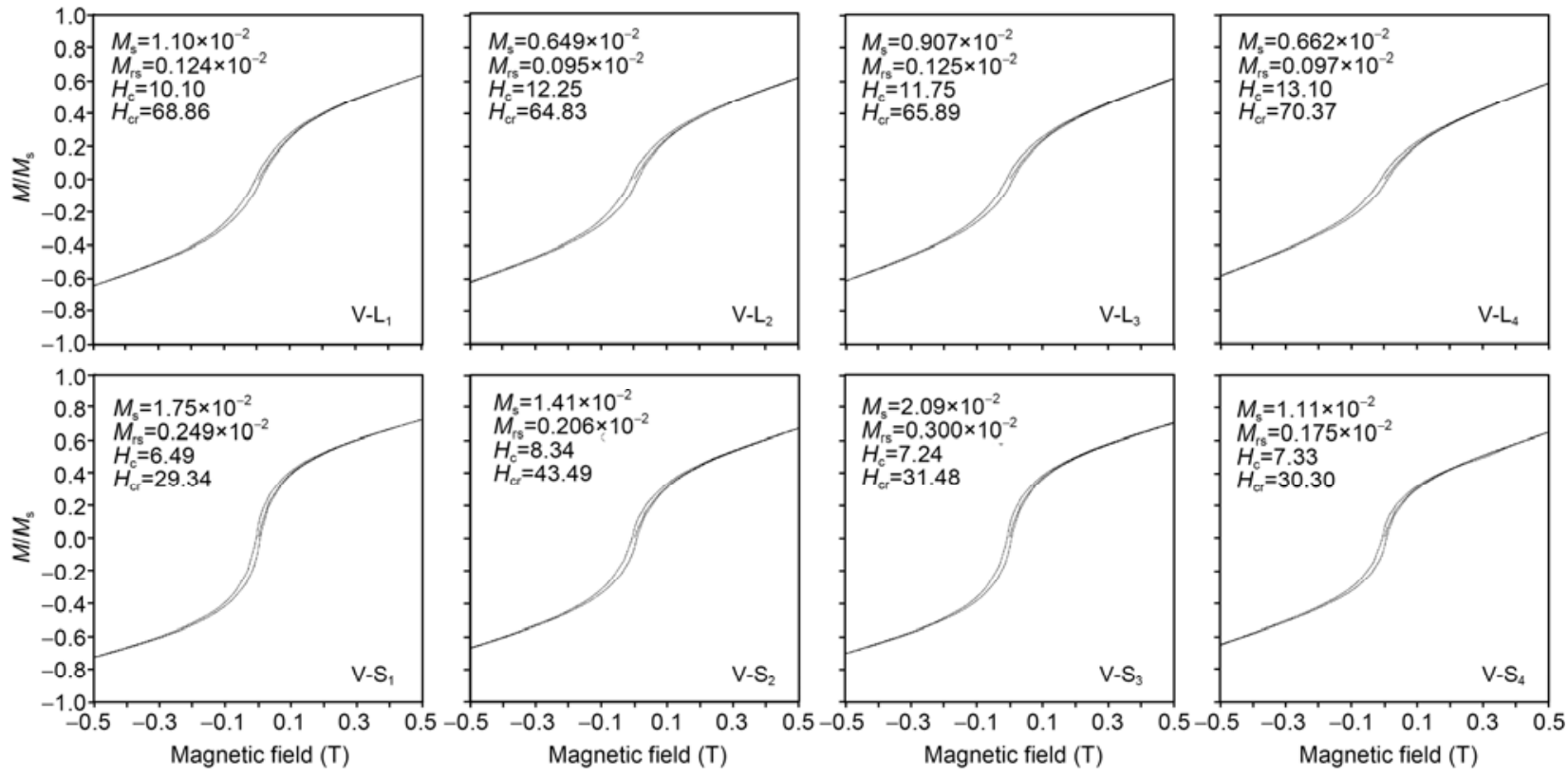

Figure 4 Hysteresis loops and related parameters. L, Loess; S, paleosol (the same below); $M_{\mathrm{s}}$, saturation magnetization $\left(\right.$ Am $\left.{ }^{2} / \mathrm{kg}\right) ; M_{\mathrm{rs}}$, saturation remanent magnetization $\left(\mathrm{Am}^{2} / \mathrm{kg}\right) ; H_{\mathrm{c}}$, coercivity $(\mathrm{mT}) ; H_{\mathrm{cr}}$, remanent coercivity $(\mathrm{mT})$. 


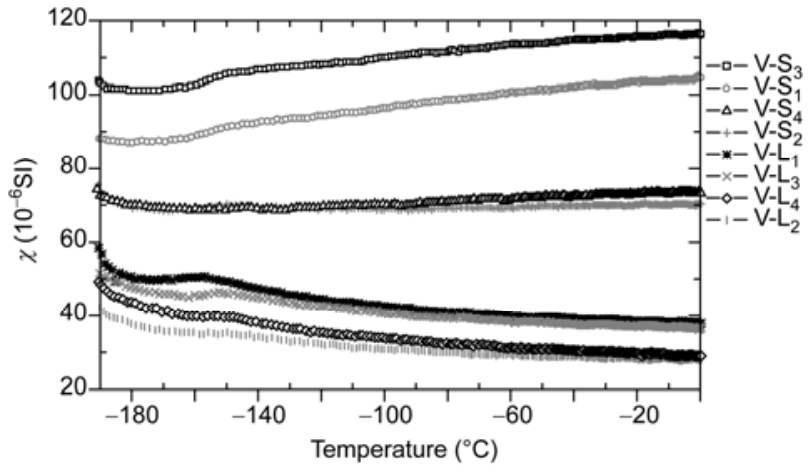

Figure 5 Low-temperature susceptibility of Serbian loess samples.

remain almost unchanged $\left(\mathrm{V}-\mathrm{S}_{4}\right.$ and $\left.\mathrm{V}-\mathrm{S}_{2}\right)$. The later behaviors indicate that SD has a dominant magnetic property, while the former behaviors indicate that there are many SP magnetic grains in the samples [26,28]. Some SD magnetic grains at room temperature are SP grains. Because of temperature cooling, these particles become SD grains. As the samples warm, the SD magnetic grains return to SP, increasing its $\chi$. Essentially, the low-temperature susceptibility curves rise or decline with increasing temperature depending on the relative content of superparamagnetic and paramagnetic materials. Since the susceptibility of superparamagnetism increases with increasing temperature, the paramagnetism has to follow Curie's law, and decline. The low-temperature susceptibility curve is the comprehensive result of the entire sample. In $\mathrm{V}-\mathrm{S}_{4}$ and $\mathrm{V}-\mathrm{S}_{2}$ samples, the low-temperature susceptibility remained unchanged, indi- cating that the SD magnetites have the absolute advantage compared with other domains (SP and MD) of magnetic minerals in the sample. $\mathrm{V}-\mathrm{S}_{3}$ and $\mathrm{V}-\mathrm{S}_{1}$ samples showing the $\chi$ increase with increasing temperature reflect superparamagnetic magnetite $(<0.03 \mu \mathrm{m})$, which is a significant proportion of the sample. This is indicated by $\chi_{\mathrm{fd}}$ in Figure 2. The IRM $_{300 ~ m T} /$ SIRM of loess samples is less than $96 \%$ (Figure 2), and the relative content of paramagnetic minerals is higher than that of the paleosols. Thus, the susceptibility declines with increasing temperature.

\subsection{High-temperature thermomagnetic curves}

Because of magnetic variation in the progress of heating and cooling, thermomagnetic curves often are used to identify magnetic mineral species by their Curie point (temperature). Figure 6 shows the thermomagnetic curves of the selected samples. In the heating process, all samples first display significant small bends near $120^{\circ} \mathrm{C}$. This bend may correspond to the existence of goethite/limonite. The second bend appeared near $300^{\circ} \mathrm{C}$, reflecting the diverse decrease in magnetization. This indicates that the thermally unstable maghemites have been transformed into stable hematite at this temperature, which leads to a decrease in magnetization. All the magnetizations decline quickly at $585^{\circ} \mathrm{C}$, indicating the existence of magnetite (Curie point $585^{\circ} \mathrm{C}$ ). Compared with the variation of magnetization at $300^{\circ} \mathrm{C}\left(\Delta M_{\mathrm{s} 300^{\circ}} \mathrm{C}\right)$ before and after heating and its percentage of magnetization before heating $\left(\Delta M_{\mathrm{s} 300^{\circ} \mathrm{C}} \%\right)$, the changes in loess samples are distinctly greater than in the paleosol samples (Table 1,
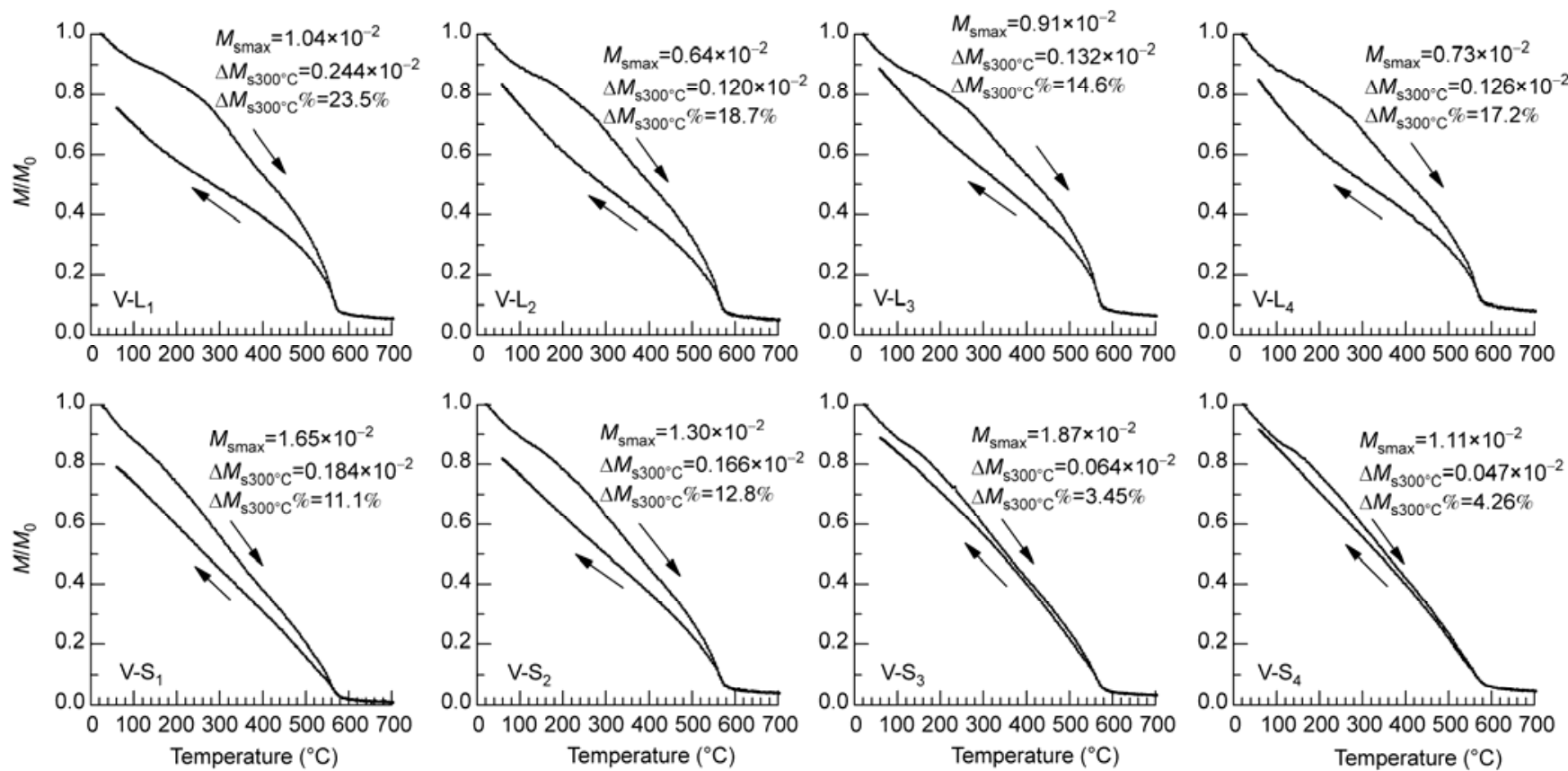

Figure 6 Thermomagnetic curves from Serbian loess and paleosols. $J_{0}$, The magnetization before heating $\left(\mathrm{Am}{ }^{2} / \mathrm{kg}\right) ; \Delta M_{\mathrm{s} 300^{\circ} \mathrm{C}}$, the magnetization difference before and after heating at $300^{\circ} \mathrm{C}\left(\mathrm{Am}^{2} / \mathrm{kg}\right) ; \Delta M_{\mathrm{s} 300^{\circ} \mathrm{C}} \%, \Delta M_{\mathrm{s} 300^{\circ} \mathrm{C}}$ as a percentage of the magnetization before/after heating. 
Table 1 The magnetic parameters of loess and paleosol sequences from $\mathrm{V}-\mathrm{L}_{1}$ to $\mathrm{V}-\mathrm{S}_{4}{ }^{\text {a) }}$

\begin{tabular}{|c|c|c|c|c|c|c|c|c|}
\hline Layer & $\chi\left(10^{-7} \mathrm{~m}^{3} / \mathrm{kg}\right)$ & $\chi_{\mathrm{fd}}(\%)$ & $M_{\mathrm{s}}\left(10^{-2} \mathrm{Am}^{2} / \mathrm{kg}\right)$ & $M_{\mathrm{rs}} / M_{\mathrm{s}}$ & $H_{\mathrm{c}}(\mathrm{mT})$ & $\Delta M_{\mathrm{s} 300^{\circ} \mathrm{C}}\left(10^{-2} \mathrm{Am}^{2} / \mathrm{kg}\right)$ & $\Delta M_{\mathrm{s} 300^{\circ} \mathrm{C}} \%$ & $H_{\mathrm{cr}} / H_{\mathrm{c}}$ \\
\hline $\mathrm{V}-\mathrm{L}_{1}$ & 3.13 & 2.99 & 1.10 & 0.11 & 10.10 & 0.24 & 23.5 & 4.33 \\
\hline $\mathrm{V}-\mathrm{S}_{1}$ & 9.98 & 10.42 & 1.75 & 0.14 & 6.49 & 0.18 & 11.1 & 4.09 \\
\hline $\mathrm{V}-\mathrm{L}_{2}$ & 1.98 & 2.69 & 0.65 & 0.15 & 12.25 & 0.12 & 18.7 & 3.72 \\
\hline $\mathrm{V}-\mathrm{S}_{2}$ & 6.42 & 8.41 & 1.41 & 0.15 & 8.34 & 0.17 & 12.8 & 3.73 \\
\hline $\mathrm{V}-\mathrm{L}_{3}$ & 2.73 & 3.41 & 0.91 & 0.14 & 11.75 & 0.13 & 14.6 & 3.65 \\
\hline $\mathrm{V}-\mathrm{S}_{3}$ & 11.15 & 10.11 & 2.09 & 0.14 & 7.24 & 0.06 & 3.45 & 3.70 \\
\hline $\mathrm{V}-\mathrm{L}_{4}$ & 2.08 & 2.24 & 0.66 & 0.15 & 13.10 & 0.13 & 17.2 & 3.48 \\
\hline $\mathrm{V}-\mathrm{S}_{4}$ & 6.58 & 10.03 & 1.11 & 0.16 & 7.33 & 0.05 & 4.26 & 3.87 \\
\hline
\end{tabular}

a) $* \Delta M_{\mathrm{s} 300^{\circ} \mathrm{C}}$, The magnetization difference before and after heating at $300^{\circ} \mathrm{C} ; \Delta M_{\mathrm{s} 300^{\circ} \mathrm{C}} \%, \Delta M_{\mathrm{s} 300^{\circ} \mathrm{C}}$ as a percentage of the magnetization before/after heating.

Figure 6). This trend may indicate that the proportions of maghemite in loess layers are higher than in paleosol layers. Specifically, in $\mathrm{V}-\mathrm{S}_{3}$ and $\mathrm{V}-\mathrm{S}_{4}$, the values of $\Delta M_{\mathrm{s} 300{ }^{\circ} \mathrm{C}} \%$ are only $3.45 \%$ and $4.26 \%$, respectively. From the changes of all thermomagnetic curves, the samples always lose magnetization after heating, indicating that there are some strong magnetic materials transformed into weak magnetic materials during heating, and these transformations are irreversible. We believe that grains behaving as maghemite are converted into hematite. In addition, the magnetization of all samples did not reach zero after $585^{\circ} \mathrm{C}$, and gradually decreased with temperature rise, indicating the existence of hematite in the samples.

\section{Discussion}

In general, the magnetic mineral species in Serbian loess are similar to those of Chinese loess. That is the strong magnetic minerals are magnetite and maghemite, and the weak minerals are goethite and hematite. However, the content of maghemite is significantly less in the Serbian loess than in the Chinese loess. High and low magnetic susceptibility in Titel loess sections respectively correspond well to the paleosol and loess layers (Figure 2). $\chi$ and $\chi_{\mathrm{fd}} \%$ have a highly positive correlation $\left(R^{2}=0.832\right)$, and demonstrate that the $\chi$ enhancement of the paleosols may be due to the finegrained maghemite/magnetite formed in the pedogenesis progress, which is consistent with the Chinese loess type. On the whole, the loess-paleosol sequences in China and Serbia both reveal the same pattern as glacial and interglacials.

\subsection{Excessive moisture also can reduce magnetic susceptibility}

Compared with the central Chinese Loess Plateau [27], the samples in the Serbian Titel loess plateau synthetic sections not only contain less thermally-unstable maghemite, but also noticeably different $\chi$ of $\mathrm{V}-\mathrm{S}_{4}$, which is lower than
$\mathrm{V}-\mathrm{S}_{3}$ (Figure 2). However, the susceptibility values of these two layers ( $\mathrm{V}-\mathrm{S}_{3}$ and $\left.\mathrm{V}-\mathrm{S}_{4}\right)$ in China are analogous, such as the Luochuan and Xifeng sections [32]. Studies on sedimentology, pedology and paleontology of the same Serbian section by Marković et al. [19] suggest gradually drier conditions over the last ca. $350 \mathrm{ka}$. This result is supported by the susceptibility curve. The peaks from $\mathrm{V}-\mathrm{S}_{3}$ to $\mathrm{V}-\mathrm{S}_{0}$ slightly decrease (Figures 2 and 7). The age of paleosol $\mathrm{V}-\mathrm{S}_{4}$ is older than ca. $350 \mathrm{ka}$. However, according to the peak value of $\chi, \mathrm{V}-\mathrm{S}_{4}$ is only about half of $\mathrm{V}-\mathrm{S}_{3}$ (Figure 2 ). Many studies mentioned above have shown that $\chi$ signals can effectively record information about paleoclimatic change. However, it is still unknown which of the following potential causes was responsible for such a distinct difference: (1) the pedogenesis of $\mathrm{V}-\mathrm{S}_{4}$ is weaker than $\mathrm{V}-\mathrm{S}_{3}$ and lead to the initial lowering of $\chi$; or (2) when $\mathrm{V}-\mathrm{S}_{4}$ developed, the moisture was excessive and produced unstable iron oxides, such as magnetite/maghemite, which transformed into goethite/limonite [9-11]. This scenario also could have caused the $\chi$ decrease.

Correlation between the susceptibility curves from (1) Serbian Titel loess sections, (2) nearby Romanian Mircea Voda section [33], (3) Bulgarian Koriten section [34], (4) Luochuan section in China, and (5) deep-sea oxygen isotope curve [35] (Figure 7) provide specific differences of investigated paleoclimatic signals. For example, Mircea Voda section $\left(44^{\circ} 19^{\prime} 15^{\prime \prime} \mathrm{N}, 28^{\circ} 11^{\prime} 21^{\prime \prime} \mathrm{E}\right.$, about $500 \mathrm{~km}$ away from the Titel section) and Koriten section $\left(43^{\circ} 56^{\prime} \mathrm{N}, 27^{\circ} 45^{\prime} \mathrm{E}\right.$, about $700 \mathrm{~km}$ away from the Titel section), both have $\chi$ values of $\mathrm{V}-\mathrm{S}_{4}$ paleosol and $\mathrm{V}-\mathrm{S}_{3}$ are very close, unlike the Titel section, which show clear differences (Figure 2). Such differences also appear in many European loess sections and deep-sea oxygen isotope curves (Figure 7). In the Luochuan section, whether $\chi$ or $\chi_{\mathrm{fd}} \%$, the $\mathrm{V}-\mathrm{S}_{4}$ paleosol are very similar with $\mathrm{V}-\mathrm{S}_{3}$, or $\mathrm{V}-\mathrm{S}_{4}$, and are even slightly higher. In the deep-sea oxygen isotope curves, the peaks of MIS11 (corresponding to $\mathrm{V}-\mathrm{S}_{4}$ ) and MIS 9 (for $\mathrm{V}-\mathrm{S}_{3}$ ) also are closely similar. Therefore, we interpreted that difference as possibly owing to: (1) climate differences among these places; and (2) similar climate change experienced. However, the different 


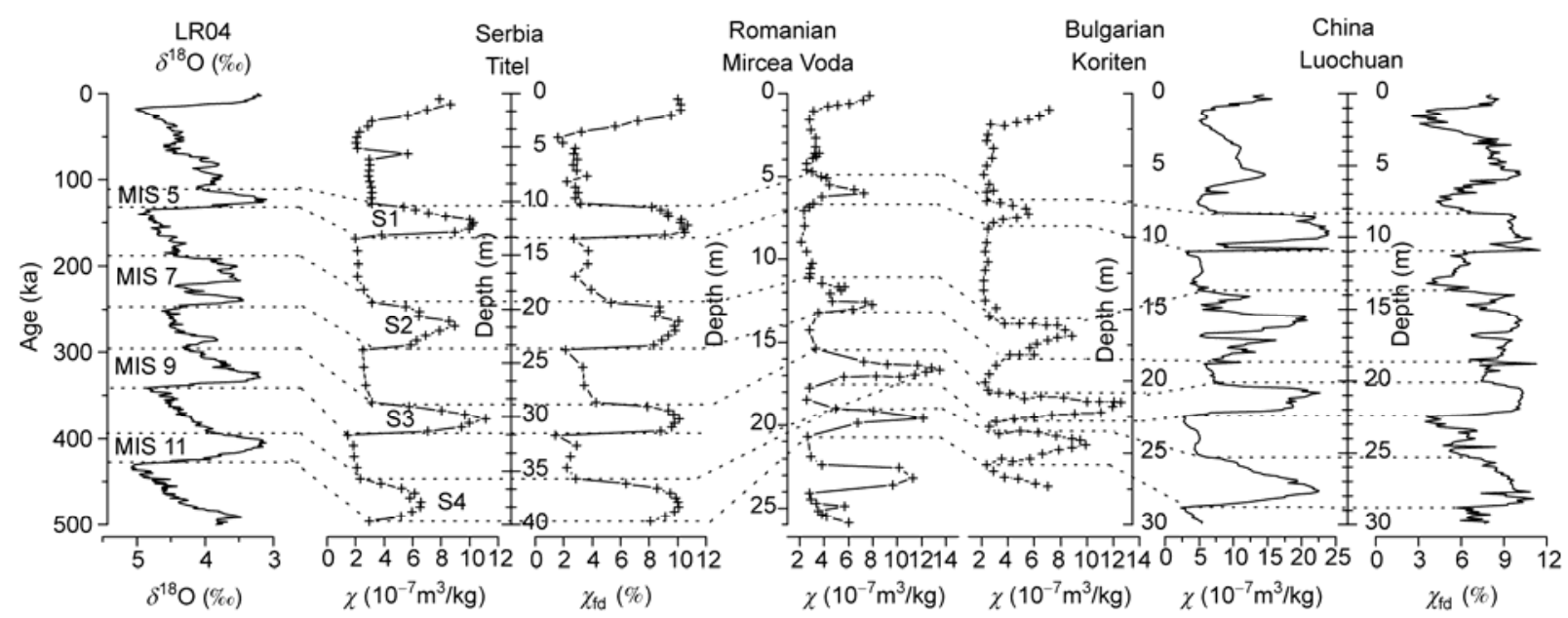

Figure 7 Correlation of the $\chi$ (including $\chi_{\mathrm{fd}} \%$ in Titel section and Luochuan section) records of the profiles Serbian Titel, Romanian Mircea Voda [33], Bulgarian Koriten [34], and Chinese Luochuan with the benthic oxygen isotope record [35].

magnetic susceptibility records may be caused by different pedogenic conditions, such as humidity variations. In the spatial range of our discussion, climate changes in the glacial-interglacial $\left(\mathrm{V}-\mathrm{S}_{3}\right.$ and $\left.\mathrm{V}-\mathrm{S}_{4}\right)$ scale is assumed, at least in relative intensity, to be similar. Thus, the clear lower $\chi$ of the Titel section $\mathrm{V}-\mathrm{S}_{4}$ compared to that of $\mathrm{V}-\mathrm{S}_{3}$ should have been caused by local climate, and likely pedogenic conditions. This suggests that the pedogenic environment or later influences (e.g. over moisture gleying conditions) in the Titel section $\mathrm{V}-\mathrm{S}_{4}$ paleosol has possibly resulted in lower $\chi$, at least with respect to relative intensity being distorted because of waterlogging. The maghemite detected in $\mathrm{V}-\mathrm{S}_{4}$ was close to zero (Figure 6), which indicates that it is likely that moisture oxidizing conditions took place during pedogenesis. This process lead to the instability of the iron oxidate maghemite, and was gradually converted onto iron hydrate. $\chi_{\mathrm{fd}} \%$ is a magnetic parameter containing extra fine grain size signals near the boundary of SP and SD particles $(0.03$ $\mu \mathrm{m})$. This always shows a higher proportion in the paleosols than in loess. Such very fine magnetic minerals were thus thought to have been formed during pedogenesis. The values of $\chi_{\mathrm{fd}} \%$ in the paleosol layers from $\mathrm{V}-\mathrm{S}_{4}$ to $\mathrm{V}-\mathrm{S}_{1}$ actually reach a similar level, and $\mathrm{V}-\mathrm{S}_{4}$ is even slightly higher than $\mathrm{V}-\mathrm{S}_{3}$ (Figure 2). This may demonstrate that $\mathrm{V}-\mathrm{S}_{4}$ experienced an analogous or slightly stronger pedogenesis than that of $\mathrm{V}-\mathrm{S}_{3}$. Although SD magnetite in $\mathrm{V}-\mathrm{S}_{4}$ is less than in the other paleosol layers, based on ARM data (Figure 2), and magnetic minerals carrying remanence (SD+MD particles) also are less (according to $\mathrm{M}_{\mathrm{s}}$ data) (Figure 2). However, low $H_{\mathrm{cr}}$ in $\mathrm{V}-\mathrm{S}_{4}$, and the relative grain size parameters (suggested by $\chi_{\mathrm{ARM}} / \chi$ and $\mathrm{SIRM} / \chi$ ) all indicate that $\mathrm{V}-\mathrm{S}_{4}$ contains finer magnetic particles than the other paleosols. These are consistent with the higher $\chi_{\mathrm{fd}} \%$ in $\mathrm{V}-\mathrm{S}_{4}$ than in others. All of these data seemly demonstrate that the paleosol layer $\mathrm{V}-\mathrm{S}_{4}$ ought to have experienced a strong pedogenesis. However, somehow its susceptibility becomes lower.
Figure 6 shows the difference between the heating and cooling curves of $\mathrm{V}-\mathrm{S}_{3}$ and $\mathrm{V}-\mathrm{S}_{4}$, which are almost close to reversible, indicating that the thermally unstable maghemite in these paleosol samples has been almost completely depleted. However, the relative amount in loess is higher. This shows that the paleosols $\mathrm{V}-\mathrm{S}_{3}$ and $\mathrm{V}-\mathrm{S}_{4}$ may be in an advanced stage of pedogenesis. In this stage, maghemite no longer increases, but gradually decreases. The $\Delta M_{\mathrm{s}}$ of $\mathrm{V}-\mathrm{S}_{4}$ is close to zero, indicating that maghemite had disappeared. This could be the reason why its magnetic susceptibility is only half of $\mathrm{V}-\mathrm{S}_{3}$. Thus, we explain the low $\mathrm{V}-\mathrm{S}_{4}$ susceptibility as very likely due to gleying by excessive moisture or ground water infiltration (Figure 8(b)). Field observations may help resolve this issue. Although the overall color of $\mathrm{V}-\mathrm{S}_{4}$ is brownish-red, a number of small gray, irregular gleying features following vertical crevices often can be observed (Figure 8(b)). The reddish color of the soils close to cracks also is less. This is the result of gleization, which is expected to be the main reason why susceptibility in the $\mathrm{V}-\mathrm{S}_{4}$ is lower than that of $\mathrm{V}-\mathrm{S}_{3}$.

\subsection{The hypothesis of "wind velocity" and "pedogenesis modification"}

Based on the positive relationship between susceptibility and pedogenesis in the Chinese Loess Plateau, the pedogenic formation of magnetic minerals hypothesis was first proposed $[3,4,27,30,36]$. This hypothesis emphasizes pedogenic contribution to forming very fine-grained maghemite/ magnetite. The "wind velocity" hypothesis was originally proposed based on Alaskan loess. With new knowledge from susceptibility of deep-sea sediments, this hypothesis interpreted the negative relationship between susceptibility and pedogenesis in Alaskan loess mainly because of variation of wind velocity in glacial and interglacial periods. Subsequently, wind tunnel trials using synthetic magnetite 


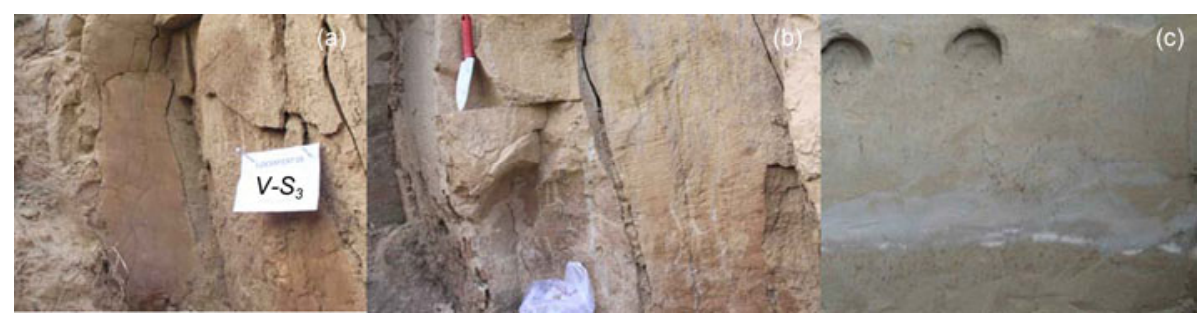

Figure 8 Serbian paleosol V-S 3 (a) and paleosol V-S $\mathrm{S}_{4}$ (b). A number of vertical gleying crevices or gleying plant root traces are observed in V-S from outcrop, that may result in lower susceptibility for $\mathrm{V}-\mathrm{S}_{4}$. Even more gleying and rusty spots can be observed in paleosol $\mathrm{S}_{1}$ in the Halfway House section, Alaska (c).

tested and verified this idea. The "wind velocity" emphasizes wind force variation and contribution of original magnetic minerals transported by wind. If the "wind velocity" hypothesis is applicable to the Alaskan loess, the condition of the wind tunnel trial should be satisfied. Thus, the magnetic minerals in the loess section are mainly from original wind transport. This also means that weathering conditions in the Alaskan loess should be dominated by physical weathering. If the original windblown magnetic minerals, especially maghemite/magnetite, have been converted into other types of minerals by chemical weathering, the susceptibility values measured today no longer record the original wind intensity. Very likely, such chemical weathering of mineral variation took place, as shown in Figure 8(c). The iron rust patches and irregular gleying soils in the Alaskan loess section commonly can be observed (Figure 8(c)). This evidence suggests that chemical weathering took place in the past. Thus, the original windblown magnetic minerals were converted to goethite as rusty spots. Conversely, these minerals dissolved in water which was washed away to become gleying spots in the section (Figure 8(c)). In fact, similar descriptions of rust and gleying in the Kurtak and Siberian sections have been reported $[6,37,38]$. Such iron rusty spots in Siberia usually are larger than those in Alaska, which also are commonly observed in outcrops of the Kurtak section, especially in both loess and paleosol layers older than MIS 3. As stated above, it is very clear that the Alaskan and Siberian loess have experienced deep chemical weathering, and that both measured magnetic susceptibility values are not original windblown signals. Thus, their magnetic signals do not link to windblown conditions, and the "wind velocity" hypothesis cannot be used for as an explanation.

\subsection{A better mode for pedogenesis modification of sus- ceptibility}

The above discussion indicates that the "wind velocity" hypothesis is not suitable for interpreting the susceptibility in the Alaskan and Siberian loess, because of observed clear chemical weathering in both places. However, this "wind velocity" hypothesis could be applied to aeolian deposits in extreme arid areas where physical weathering is a dominant process. In fact, the magnetic component of a loess paleosol sequence from anywhere can be divided into primary and secondary parts. In different places and times, the contents of these two parts, or their ratio, vary. For example, in the Chinese Loess Plateau, the temperature and humidity conditions in the southeast were different than in the northwest. Thus, the secondary part (fine-grained maghemite and magnetite formed in pedogenesis) had a greater proportion. Conversely, in the northwest, climate conditions were significantly worse (especially low humidity), and chemical pedogenesis was weak. In addition, such arid areas were closer to the aeolian source region, which implies that the primary part (original aeolian components) is a greater proportion, and physical weathering is dominant there.

The study of the topsoil in Ili basin has shown that, $\chi$ is inversely related to $\chi_{\mathrm{fd}} \%$, and $\chi$ values have a negative correlation with average annual rainfall [39]. We believe that this situation possibly reflects wind velocity variations. Combined with the other studies in arid regions, a completely modified mode for "an idealized relationship between effective precipitation and modification of the ferromagnetic content during pedogenesis" [9] is shown in Figure 9. The magnetic susceptibility, as a physical parameter, has no essential relation to climate. Its value depends on the magnetic mineral types, quantities and particle size distributions. The original aeolian magnetic minerals begin the secondary pedogenic process when they deposit and stabilize in an area. After deposition, the micro-environmental pedogenic conditions (especially temperature and humidity) in topsoil control the direction of pedogenesis. In this process, the temperature and humidity need to be considered, and the soil $\mathrm{pH}$ and Eh also may sometime be considered. However, for the convenience of this discussion, we have simplified all relevant elements as only moisture or humidity. This idealized relationship between magnetic susceptibility and effective humidity can be divided into three regions (A, B, C), which are separated by two critical values of $E$ and $F$ (Figure 9). Region A represents loess deposition near the aeolian source. In this area, the climate is extremely arid and pedogenesis is weak. Thus, physical weathering is dominant, such as in loess paleosols in most parts of Xinjiang, where magnetic susceptibility and grain size show a positive correlation $[39,40]$. This area should be a good place to apply the "wind theory" hypothesis. Far away from 


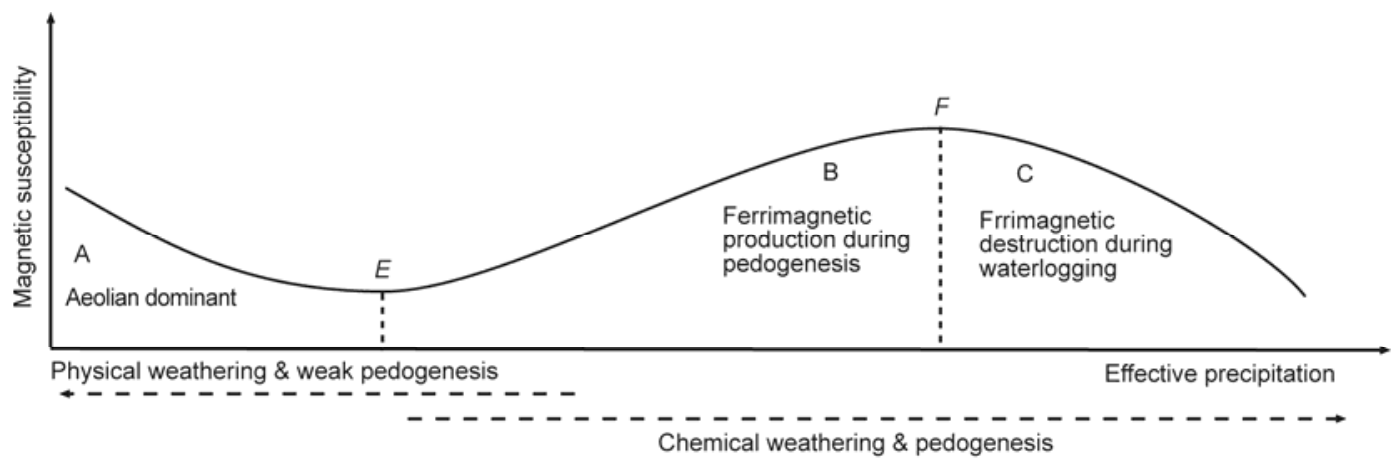

Figure 9 Idealizsed diagram showing a relationship between magnetic susceptibility and effective precipitation.

the loess source, the effective moisture increases, and chemical weathering is enhanced, while physical weathering weakens. The Chinese Loess Plateau (region B) and moist high-latitude Siberian/Alaskan areas (region C) can be considered as the two extreme end-members between susceptibility and the effective moisture. Below the critical value F, the pedogenesis environment is under oxidizing conditions. Such oxidizing pedogenesis is suitable for the formation of iron oxidate, such as very fine-grained maghemite and magnetite. This case applies to most of the Chinese loess and European loess, where the susceptibility values show a positive relation with pedogenic development. If the moisture exceeds the critical value $F$, the micro-environment of pedogenesis will be under moist oxidizing or even reducing conditions. Furthermore, the iron oxides are derived from aeolian sources and are always in a depleted state because of excess moisture. This results in iron oxidate instability and gradual transformation to iron hydrate goethite (and finally dissolved by gleying), such as rusty spots and irregular gleying observed in the Siberian and Alaskan loess. It is clear that, if the humidity conditions in a region always fluctuate between regions $\mathrm{B}$ and $\mathrm{C}$, but surround the critical value $F$, then the relationship between magnetic susceptibility and paleoclimate would be irregular, or not clear, such as the loess in New Zealand, Argentina and even on the southern edge of the Chinese Loess Plateau (Figure 9). It is noticeable that the critical value has a variety of terms. For example, Lü et al. [41], based on a Chinese topsoil study, considered that the value may be near $1100 \mathrm{~mm}$. Maher and Thompson [42] thought the highest boundary of magnetization increase is near $1500 \mathrm{~mm}$, and the dissolving boundaries may be higher.

\section{Conclusions}

(1) The relation between magnetic susceptibility and Serbian loess paleosols is generally similar to the Chinese loess: low values in the loess layers, and high values in the paleosol layers. Such a positive correlation suggests a similar mechanism of formation of the Chinese loess, and indicates that the magnetic susceptibility enhancement in soils is mainly due to very fine maghemite/magnetite formation during pedogenesis in Serbian loess.

(2) The magnetic minerals in the Serbian loess and paleosol also are similar to those of the Chinese loess: high susceptibility minerals are magnetite and maghemite, and low susceptibility minerals are hematite and goethite/limonite.

(3) Analysis of low-temperature susceptibility shows that the Serbian loess may contain more SP and SD magnetite and maghemite particles. However, the proportion of maghemite in paleosols is distinctly lower than that in the loess layers, especially in paleosol $\mathrm{V}-\mathrm{S}_{3}$ and $\mathrm{V}-\mathrm{S}_{4}$. This suggests that maghemite may have reached unstable pedogenic moisture conditions.

(4) The $\chi$ difference between loess layers and paleosol layers is closely related to pedogenesis. The fine-grained ferrimagnetic and ferromagnetic minerals in samples increase as pedogenesis develops, which leads to MS increases. However, during V-S3 and V-S4 formation, excess moisture (compared with $\mathrm{V}-\mathrm{S} 1$ and $\mathrm{V}-\mathrm{S} 2$ ) is expected, and maghemite becomes unstable because of limited irregular gleying.

This work was supported by the National Natural Science Foundation of China (40830105, 41072124 and 41021091) and the Natural Science Foundation of Gansu Province (0710KJZ A024).

1 Liu T S. Loess and the Environment (in Chinese). Beijing: Science Press, 1985. 1-481

2 Liu T S. Loess and environment. J Xi' an Jiaotong Univ (Soc Sci), 2002, 22: 7-11

3 Zhou L P, Oldfield F, Wintle A G, et al. Partly pedogenic origin of magnetic variations in Chinese Loess. Nature, 1990, 346: 737-739

4 Liu X M, Liu T S, Heller F, et al. Frequency-dependent susceptibility of loess and Quaternary paleoclimate (in Chinese). Quat Sci, 1990, 1: 42-50

5 Begét J E, Hawkins D B. Influence of orbital parameters on Pleistocene loess deposition in central Alaska. Nature, 1989, 337: 151-153

6 Matasova G, Petrovsky E, Jordanova N, et al. Magnetic study of Late Pleistocene loess/palaeosol sections from Siberia: Palaeoenvironmental implications. Geophys J Int, 2001, 147: 367-380

7 Zhu R X, Shi C D, Suchy V, et al. The magnetic properties of Czechic loess and its paleoclimatic significance. Sci China Ser D-Earth Sci, 2001, 31, 146-154

8 Ding Z L, Ranov V, Yang S L, et al. The loess record in southern Ta- 
jikistan and correlation with Chinese Loess. Earth Planet Sci Lett, 2002, 200: 387-400

9 Liu X M, Hesse P, Rolph T, et al. Properties of magnetic mineralogy of Alaskan loess: evidence for pedogenesis. Quat Int, 1999, 62: 93102

10 Liu X M, Liu T S, Xia D S, et al. The analysis of two different padogenesis models in reductive and oxidative conditions record by Chinese and Siberia Loess. Sci China Ser D-Earth Sci, 2007, 37: 13821391

11 Liu X M, Xia D S, Liu T S, et al. Discussion on two models of paleoclimatic records of magnetic susceptibility of Alaskan and Chinese loess (in Chinese). Quat Sci, 2007, 27: 210-220

12 Heil Jr C W, King J W, Zárate M A, et al. Climatic interpretation of a 1.9 Ma environmental magnetic record of loess deposition and soil formation in the central eastern Pampas of Buenos Aires, Argentina. Quat Sci Rev, 2010, 29: 2705-2718

13 Xia D S, Chen F H, Ma J Y, et al. Magnetic characteristics of loess in the Ili area and their environmental implication (in Chinese). Quat Sci, 2010, 30: 902-909

14 Begét J E, Stone D B, Hawkins D B. Paleoclimatic forcing of magnetic suscep tibility variations in Alaskan loess during the Late Quaternary. Geology, 1990, 18: 40-43

15 Marković S B, Hambach U, Stevens T, et al. The last million years recorded at the Stari Slankamen (Northern Serbia) loess-paleosol sequence: Revised chronostratigraphy and long-term environmental trends. Quat Sci Rev, 2011, 30: 1142-1154

16 Bronger A. Correlation of loess-paleosol sequences in east and central Asia with SE central Europe: Towards a continental Quaternary pedostratigraphy and paleoclimatic history. Quat Int, 2003, 106-107: 11-31

17 Marković S B, Bokhorst M P, Vandenberghe J, et al. Late Pleistocene loess-palaeosol sequences in the Vojvodina region, north Serbia. J Quat Sci, 2008, 23: 73-84

18 Marković S B, Hambach U, Catto N, et al. Middle and Late Pleistocene loess sequences at Batajnica, Vojvodina, Serbia. Quat Int, 2009, 198: 255-266

19 Marković S B, Oches E, Sümegi P, et al. An introduction to the Middle and Upper Pleistocene loess-paleosol sequence at Ruma brickyard, Vojvodina, Serbia. Quat Int, 2006, 149: 80-86

20 Bokhorst M P, Beets C J, Marković S B, et al. Pedo-chemical climate proxies in Late Pleistocene Serbian-Ukranian loess sequences. Quat Int, 2009, 198: 113-123

21 Antoine P, Rousseau D D, Fuchs M, et al. High-resolution record of the last climatic cycle in the southern Carpathian Basin (Surduk, Vojvodina, Serbia). Quat Int, 2009, 198: 19-36

22 Schmidt E D, Machalett B, Marković S B, et al. Luminescence chronology of the upper part of the Stari Slankamen loess sequence (Vojvodina, Serbia). Quat Geochronol, 2010, 5: 137-142

23 Stevens T, Marković, S B, Zech M, et al. Dust deposition and climate in the Carpathian Basin over an independently dated last glacial-interglacial cycle. Quat Sci Rev, 2011, 30: 662-681

24 Marković S B, Jovanović M, Mijović D, et al. Titel Loess plateaugeopart. Proceedings of 2nd Conference on the geoheritage of Serbia,
Belgrade. 2004, June 22-23, 177-184

25 Zeeden C, Hark M, Hambach U, et al. Depressions on the Titel Loess Plateau: Form-pattern-genesis. Geogr Pannoni, 2007, 11: 4-8

26 Thompson R, Oldfield F. Environmental Magnetism. London: George Alien \& Unwin, 1986

27 Liu X M, Shaw J, Liu T S, et al. Magnetic mineralogy of Chinese loess and its significance. Geophys J Int, 1992, 108: 301-308

28 Dunlop D J, Özdemir Ö. Rock Magnetism: Fundamentals and frontiers. Cambridge: Cambridge University Press, 1997. 573

29 Marković S B, Hambach U, Stevens T, et al. Relating the astronomical timescale to the loess-paleosol sequences in Vojvodina, Northern Serbia. In: Berger A, Mesinger F, Sijacki D, eds. Climate Change: Inferences from Paleoclimate and Regional Aspects. Vienna: SpringerVerlag, 2012

30 Liu X M, Rolph T, Bloemendal J, et al. Quantitative estimates of paleoprecipitation at Xifeng in the Loess Plateau of China. Palaeogeogr Palaeoclimatol Palaeoecol, 1995, 113: 243-248

31 Liu X M, Heller F, Xu T C, et al. Low-temperature rock magnetism and the magnetic particle characteristics of Chinese loess. Chin Sci Bull, 1991, 2: 125-128

32 Liu X M, An Z S, Rolph T, et al. Magnetic properties of the Tertiary red clay from Gansu Province, China and its paleoclimatic significance. Sci China Ser D-Earth Sci, 2001, 44: 635-651

33 Buggle B, Hambach U, Glaser B, et al. Stratigraphy and spatial and temporal paleoclimatic trends in Southeastern/Eastern European loesspaleosol sequences. Quat Int, 2009, 196: 86-106

34 Jordanova D, Petersen N. Palaeoclimatic record from a loess-soil profile in northeastern Bulgaria-II. Correlation with global climatic events during the Pleistocene. Geophys J Int, 1999, 138: 533-540

35 Lisiecki L E, Raymo M E. A Pliocene-Pleistocene stack of 57 globally distributed benthic $\delta^{18} \mathrm{O}$ records. Paleoceanography, 2005, 20: 1003-1020

36 Heller F, Liu T S. Magnetism of Chinese loess deposits. Geophys J R, 1984, 77: 125-141

37 Chlachula J, Rutter N W, Evans M E. A late Quaternary loesspalaeosol record at Kurtak, southern Siberia. Can J Earth, 1997, 34 : 679-686

38 Chlachula J, Evans M E, Rutter N W. A magnetic investigation of a late Quaternary loess/palaeosol record in Siberia. Geophys J Int, 1998, 132: 399-404

39 Guo X L, Liu X M, Lü B, et al. Comparison of topsoil magnetic properties between the loess region in Tianshan Mountains and Loess Plateau, China, and its environmental significance (in Chinese). Chin J Geophys, 2011, 54: 1854-1862

40 Song Y G, Shi Z T, Fang X M, et al. Loess magnetic properties in the Ili Basin and their correlation with the Chinese Loess Plateau. Sci China Ser D-Earth Sci, 2010, 53: 419-431

41 Lü H Y, Han J M, Wu N Q, et al. The magnetic susceptibility of Chinese modern soils and their paleoclimatic significance (in Chinese). Sci China Ser B, 1994, 24: 1290-1297

42 Maher B A, Thompson R. Paleorainfall reconstructions from pedogenic magnetic susceptibility variations in the Chinese loess and paleosols. Quat Res, 1995, 44: 383-391

Open Access This article is distributed under the terms of the Creative Commons Attribution License which permits any use, distribution, and reproduction in any medium, provided the original author(s) and source are credited. 